\title{
EXPERT INSIGHT
}

\section{An Interview with Alex C. Michalos \\ Professor Emeritus, Political Science, University of Northern British Columbia}

\author{
Interview by \\ Dan Weijers \\ 15 April 2014
}

\section{What got you interested in wellbeing research?}

I began my academic career in philosophy of science, with a dissertation on the Popper/Carnap controversy on measuring the acceptability of scientific theories. So I did a lot of work on probability theory. Then I moved on to decision and voting theory. Somewhere along the way I read the pragmatists William James, Ralph Barton Perry, John Dewey and Clarence Irving Lewis, and I got intrigued with the idea of a rigorous pragmatic naturalistic theory of value along the lines of Perry (1926) and Lewis (1946) in particular.

I was a visiting professor at the University of Pittsburgh in 1969 and my friend there, Nicholas Rescher, was preparing a manuscript for his book on welfare. I was struck by the way he integrated statistical data and philosophical analysis. At the same time I was reading about practical decision making from Herbert Simon $(1945,1957)$ and the new social indicators movement. I became a charter member of the Public Choice Society, met Mancur Olson and was convinced that if I worked with people in that movement, I could mix my philosophical and statistical interests perfectly.

What I have been doing since the late $60 \mathrm{~s}$, as a pragmatist and consequentialist from a philosophical point of view, is trying to define and measure the dependent variable in searches for a good life or a good quality of life, what some people call general wellbeing now.

\section{What do you take "wellbeing" to mean?}

I identify wellbeing with a life of good quality, all things considered. There is no rule book about what should be included in the "all things considered". So it takes a lot of conceptualizing and measuring to get a generic package that will be acceptable to most individuals and societies. When I started back in the 60s, I thought it might take 25 years or so before the world would reach some agreement on what elements to include in the dependent variable. Then in the 80s the sustainable development movement came along and it became clear to me that 25 years would not be enough. Maybe it's a totally open-ended human quest, altering a bit with time and across cultures. Certainly the root issues driving what we have been doing for the past 50 years can be traced back to ancient scholars in the fifth and fourth centuries BCE, i.e., the search for a clear view of a good life and a good way to live.

I am convinced that a good quality of life or wellbeing is precisely the dependent variable needed to measure sustainable development. It is precisely what we want or should want to sustain. We are a long way from agreement on the dependent variable and most people do not even seem to see the connection between quality of life research and sustainable development. Although in the crucial parts of the Bruntland Commission report, where it talks about satisfying 
current needs without reducing options for the next generation, a few sentences down on the same page it also talks about improving quality of life as the important thing; not just satisfying needs, but meeting aspirations for a good life. Something like that.

\section{Why is wellbeing research important?}

For a pragmatist and consequentialist, it is impossible to assess the value of our lives, decisions we make about good and evil, about a good life and a good society unless we have a good understanding of the dependent variable. We need a clear vision of where we want to go, how we think things should be and the best way to get there in a sustainable way.

\section{What is the most important wellbeing-related finding from your research?}

I think there are two. First, I assume that robust theories are important for driving scientific research and I still think multiple discrepancies theory points the way toward a more comprehensive, coherent, integrated, conceptually sound and empirically well-supported theory of subjective wellbeing. When I invented it, I thought I was giving a new foundation to classical utility theory, an empirical foundation in the tradition of Perry and Lewis for defining naturalistic value and through it satisfaction and happiness. I later realized that there was circularity built into the theory. So it could not deliver a purely naturalistic theory. Besides, I no longer believe in a naturalistic theory. I think we always smuggle in some a priori stuff when we define value, wellbeing, or quality of life.

People working in the logical positivist tradition have been quite happy to conduct research with a relatively slim understanding of 'theory' and little emphasis on it, and I do believe that a lot of good research can be done with such understanding. Generally speaking, positivists adopt a rigid distinction between facts and values, and between observation terms and theoretical terms, the need for value-free science and scientific research, scientific explanation based on the model of sound arguments, clearly distinguishable scientific laws and theories, and the possibility of theory-free measurement. I confess to being a teenage positivist and some of the boy remains in the man, but I am convinced that robust theories are still important and should be high on our research agendas. Such theories provide context and allow us to see not only essential elements but the need to find relationships, making some elements more influential than others and some lines of investigation particularly helpful for breaking new ground.

Second, there is a so-called gold standard self-report measure of overall health status in the health-related quality of life research tradition called Short Form 36 (SF-36), which is also used by many people as a measure of quality of life. I demonstrated in a few publications with survey data that there is a huge difference between good health and a good life. The explanatory predictors of both things are clearly distinct. So people should stop using SF-36 to measure quality of life. I don't think it will change anyone's behaviour, but I do think what I demonstrated is very important. Life is like that sometimes.

\section{What are you working on right now?}

Well, the 12 volume Encyclopedia of Quality of Life and Well-Being Research (Spinger) came out in March and I am working a bit to get the word out through various outlets, newspapers, newsletters, listserves. Along with a couple dozen others, I am working on parts of a history of wellbeing. I think I will use some of what I am writing about ancient views of wellbeing for a short monograph and I will use some of what I am writing on North American research for an article on Canadian milestones. I have a province-wide survey of 15 -year-olds' knowledge, 
attitudes and behaviours around sustainable development. I am still editor in chief of the Journal of Business Ethics, the most frequently cited journal in the world devoted to business ethics. I started it over 30 years ago to pick up research being done on quality of work life and on corporate social accounting. I have never given business ethics more than about 10 or $15 \%$ of my research time, but that journal is much larger than Social Indicators Research.

\section{What do you think the next big thing in wellbeing research will be?}

I don't know what it will be but I think what it should be is continuing to get agreement on the nature of the dependent variable and on its connection to sustainable development. Once we get clear about what it is we want to sustain, we can measure what it takes to keep the thing going given the rates of change of required inputs to desired outputs.

Judging from the report by Stiglitz, Sen and Fitoussi, I think we are still held back by economists and policy makers who can't see much beyond what economists say. With some exaggeration I think that in part one of their report they told us what we already knew (limits of GDP), in part two they told us quite a bit less than we know (about quality of life) and in part three they told us to ask someone else (about sustainable development). A pretty disappointing result from some first-rate economists.

\section{What are the main benefits of interdisciplinary research on wellbeing?}

There is no other or more promising way. Regarding the quantity of life we are notoriously limited to one per person, but the quality of life is as varied as there are perspectives from which it can be assessed. No one discipline can capture all the elements and their relationships.

\section{What would the ideal census question on wellbeing be and why?}

If we are limited to only one, I think we will be in dangerous territory. In several publications I have shown that measures of health, standard of living, quality of life, life satisfaction and happiness do not capture exactly the same things. If we use only one measure for our dependent variable, we are bound to get distorted views about what is most important and how all the important things are related. I suppose most money is behind a single life satisfaction or happiness question, but these are very limited in what they capture. We really do need subjective and objective indicators in order to distinguish real paradise and hell from a fool's paradise and hell. Either one sort of indicator alone cannot do the work of adequately measuring quality of life or wellbeing.

The World Happiness Report, edited by John Helliwell, Richard Layard and Jeffrey Sachs, had five measures of their dependent variable presumed to capture overall wellbeing of some sort, namely, Cantril's ladder, life satisfaction, happiness, positive affect and negative affect. Examining their list of explanatory variables, one finds very few if any measures of human agency, e.g., measures of people's perceived wants and needs, of their expectations, hopes and fears, efforts, equity, past experiences, constraints and resources. A lot of resources were invested in measuring relatively objective features of people's lives to explain their perceived wellbeing, but what people tried to make or made of those features was largely neglected.

\section{What parts of your research have brought you the most enjoyment and/or satisfaction?}

What I like most about research is learning new things. I especially like discovering things that, so far as I know, nobody else has found. I suspect this view would be similar to most scholars as far back as Anaxagoras. I also enjoy expressing my views in sentences that I think are particularly 
graceful, if that's the right word. T. S. Eliot talked about the music of prose and I think there is something to that. Sometimes the ideas turn into sentences that are quite pleasant to read. If you look at Bertrand Russell's manuscripts, you find that he usually hit the expressions he wanted on the first shot. If you looked at mine, before computers, you would find writes and re-writes. I usually have a hard time getting the right expression first time around, although I must say that the older I get, the easier it gets to hit the right mark first off. Hopefully, this is not a sign that I am losing my taste or standards, though that would not surprise me given all the other things I have lost to age. The other thing I like most about my research is the opportunity it has given me to know and work with people all over the world with similar interests. There is something special, I think, about working with a team or another person. Maybe it is related to the essential sociality of our species, although I know of several good scholars who work on their own and prefer that. In fact, for some, it is best for all of us if they keep to themselves.

\section{What parts of your research have brought you the most dissatisfaction and/or displeasure?}

Writing proposals for research funding against very bad odds of success. Then not getting funded. Having my work evaluated by people who clearly know less than I do about the subject. Having papers submitted to journals and having them neglected by editors who were not managing the store well. The worst case I experienced was with a paper I wrote called 'Efficiency and morality'. Thirteen months after submitting the paper, I wrote to find its status. The editor said he mislaid it and asked me to re-submit. I wrote back that I did not think he understood either efficiency or morality, and published the paper somewhere else.

I have always found longer works more satisfying than shorter ones. However, with long works I always have had a troublesome feeling that I would drop dead before finishing the piece. Then, when it is finished, I am troubled by the thought that no one will read it or that those who do read it will find it stinks. I am pretty sure some of my work has met both fates. When I was working on my 5-volume North American Social Report (1980-82), I started looking for a publisher after I finished the first 2 volumes. After 57 rejections, I really worried a lot about the time I was investing and the likelihood that nothing would come of it. Then Reidel accepted it and I worried about finishing it, etc. It took me 12 years to write that treatise. It did win the Secretary of State's Award for Interdisciplinary Reseach, but I doubt that anyone has read the whole thing. Still, it was a great learning experience.

After I published my Citation Classics from Social Indicators Research (2005), I had a look at the 168 or so citations to my paper on multiple discrepancies theory (1985). I found that about $70 \%$ of the citations were perfunctory. Some authors clearly had never read my paper. Some reported that I said exactly the opposite of what I did say. I still think citation analysis has some validity and proper uses. My wife had the impression that I did a lot of self-citing and I had been convinced that I did too. Then I found I self-cited about $5 \%$ of the time compared to something like $22 \%$ for average authors. That kind of thing is nice to know.

\section{Is there anything else you would like to comment on?}

For years I preferred the spelling 'wellbeing' to the longer 'well-being'. After we gathered up most of the 2200 or so articles for the encyclopedia, my friend at Springer did some citation research and discovered that there was something like 6 times more citations to well-being than to quality of life, and more citations to well-being than to wellbeing. So we added 'and WellBeing' to the name of the encyclopedia. Although I think of well-being and quality of life as pretty 
much synonyms, a lot of people apparently don't. So we went for the bigger pool. The Oxford English Dictionary uses well-being, but other dictionaries use wellbeing. We also noticed that some people use 'quality of life' and others 'quality-of-life' more or less inconsistently. So we just stayed with quality of life.

About Alex C. Michalos (provided by Alex C. Michalos, April 2014)

Alex is Emeritus Professor in Political Science from the University of Northern British Columbia, where he taught from 1994-2001. He was Professor of Philosophy at the University of Guelph (Ontario) from 1966 to 1994, and has held positions at several other universities. His awards include a Gold Medal for Achievement in Research (2004) from the Social Sciences and Humanities Research Council of Canada (the Council's highest honour), and he is a Member of the Order of Canada, C.M. (2010).

\section{Author}

Dan Weijers

Victoria University of Wellington

Dan.Weijers@vuw.ac.nz

\section{References}

Lewis, C. L. (1946). Analysis of Knowledge and Valuation. LaSalle: Open Court Pub. Co.

Perry, R. B. (1926). General Theory of Value. Cambridge: Harvard University Press.

Simon, H. A. (1945). Administrative Behavior. New York: MacMillan Co.

Simon, H. A. (1957). Models of Man. New York: John Wiley and Sons, Inc. 